\title{
Pain characteristics and demographics of patients attending a university-affiliated pain clinic in Toronto, Ontario
}

\author{
Angela Mailis-Gagnon MSc MD FRCPC ${ }^{1,2}$, Balaji Yegneswaran MBBS ${ }^{1}$, SF Lakha MSc ${ }^{1}$, Keith Nicholson PhD¹, \\ Amanda J Steiman BSc${ }^{1}$, Danny Ng BSc${ }^{1}$, Marios Papagapiou MSc${ }^{1}$, Margarita Umana MD ${ }^{1}$, \\ Tea Cohodarevic MD FRCP ${ }^{1}$, Mateusz Zurowski MD FRCP ${ }^{1}$
}

\begin{abstract}
A Mailis-Gagnon, B Yegneswaran, K Nicholson, et al. Pain characteristics and demographics of patients attending a university-affiliated pain clinic in Toronto, Ontario. Pain Res Manage 2007;12(2):93-99.
\end{abstract}

BACKGROUND: Pain clinics tend to see more complex chronic pain patients than primary care settings, but the types of patients seen may differ among practices.

OBJECTIVE: The aim of the present observational study was to describe the pain and demographic characteristics of patients attending a university-affiliated tertiary care pain clinic in Toronto, Ontario.

METHODS: Data were collected on 1242 consecutive new patients seen over a three-year period at the Comprehensive Pain Program in central Toronto.

RESULTS: Musculoskeletal problems affecting large joints and the spine were the predominant cause of pain (more prevalent in women), followed by neuropathic disorders (more prevalent in men) in patients with recognizable physical pathology. The most affected age group was in the 35- to 49-year age range, with a mean pain duration of 7.8 years before the consultation. While $77 \%$ of the Comprehensive Pain Program patients had relevant and detectable physical pathology for pain complaints, three-quarters of the overall study population also had significant associated psychological or psychiatric comorbidity. Women, in general, attended the pain clinic in greater numbers and had less apparent physical pathology than men. Finally, less than one in five patients was employed at the time of referral.

CONCLUSIONS: The relevance of the data in relation to other pain clinics is discussed, as well as waiting lists and other barriers faced by chronic pain patients, pain practitioners and pain facilities in Ontario and Canada.

Key Words: Chronic pain; Demographics
Les caractéristiques de la douleur et la démographie des patients qui fréquentent une clinique de la douleur affiliée à une université de Toronto, en Ontario

HISTORIQUE : Les cliniques de la douleur tendent à recevoir plus de patients atteints de douleurs chroniques complexes que les établissements de soins primaires, mais le type de patients peut différer entre les pratiques.

OBJECTIF : La présente étude d'observation vise à décrire la douleur et les caractéristiques démographiques des patients qui fréquentent une clinique de la douleur de soins tertiaires affiliée à une université de Toronto, en Ontario.

MÉTHODOLOGIE : On a colligé les données auprès de 1242 nouveaux patients consécutifs qui ont été suivis pendant trois ans par le programme intégré de la douleur au centre de Toronto.

RÉSULTATS : Les troubles musculosquelettiques des grosses articulations et de la colonne vertébrale étaient les principales causes de douleur (plus prévalentes chez les femmes), suivies des troubles neuropathiques (plus prévalents chez les hommes) chez les patients atteints d'une pathologie physique identifiable. Le groupe d'âge le plus touché se situait dans la plage des 35 à 49 ans, la durée moyenne de la douleur étant de 7,8 ans avant la consultation. Bien que $77 \%$ des patients participant au programme intégré de la douleur souffraient d'une pathologie physique pertinente et décelable expliquant les plaintes de douleur, les trois quarts de la population globale à l'étude présentaient une comorbidité psychologique ou psychiatrique connexe. En général, plus de femmes fréquentaient la clinique de la douleur et présentaient des pathologies physiques moins apparentes que les hommes. Enfin, moins d'un patient sur cinq occupait un emploi au moment de l'aiguillage.

CONCLUSIONS : On aborde la question de la pertinence des données par rapport à celles d'autres cliniques de la douleur, de même que la question des listes d'attente et des autres obstacles qu'affrontent les patients souffrant de douleurs chroniques, les praticiens de la douleur et les établissements de la douleur en Ontario et au Canada.
$\mathrm{C}$

Chronic pain, defined as pain lasting for longer than three months (or six months in the Diagnostic and Statistical Manual of Mental Disorders, Fourth Edition - Text Revision [DSM-IV-TR]) (1), has emerged as one of the most significant concerns of the health care system (2). It is estimated that $80 \%$ of physician visits are prompted by complaints of pain (3), and between $10 \%$ and $55 \%$ of Western societies suffer from chronic noncancer pain (CNCP) (4).

Studies have demonstrated that patient demography and characteristics not only influence the outcomes of clinical treatments, but can also help the health care provider tailor specific treatments to different patient populations $(5,6)$. Outcomes of therapeutic interventions, including both surgical and medical treatments, vary, depending on multiple factors relating to patients, providers and the health care system.

Patients with chronic pain are treated in a variety of settings including primary care, specialty hospital clinics (eg, diabetic clinics, multiple sclerosis clinics, etc) and pain clinics (community- or hospital-based). Compared with CNCP patients seen in primary care settings, patients seen in specialty

${ }^{1}$ Comprehensive Pain Program, Toronto Western Hospital; ${ }^{2}$ Krembil Neuroscience Centre, Toronto Western Hospital, University of Toronto Centre for the Study of Pain, Toronto, Ontario

Correspondence: Dr Angela Mailis-Gagnon, Comprehensive Pain Program, Toronto Western Hospital, 4F811, 399 Bathurst Street, Toronto,

Ontario M5T 2S8. Telephone 416-603-5380, fax 416-603-5725, e-mail angela.mailis@uhn.on.ca 


\begin{tabular}{|c|c|}
\hline Characteristics & \\
\hline \multicolumn{2}{|l|}{ Population } \\
\hline Total, n & 1242 \\
\hline Male patients, $n$ & 534 \\
\hline Female patients, $n$ & 708 \\
\hline GTA to non-GTA ratio & $2.14: 1$ \\
\hline Female to male ratio & $1.33: 1$ \\
\hline Mean age, years & 48.5 \\
\hline \multicolumn{2}{|l|}{ Most affected group, \% } \\
\hline 20-34 years & 14.10 \\
\hline $35-49$ years & 43.32 \\
\hline 50-64 years & 26.97 \\
\hline$>65$ years & 14.65 \\
\hline \multicolumn{2}{|l|}{ Marital status, \% } \\
\hline Married & 58.0 \\
\hline Common-law & 5.0 \\
\hline Single & 20.0 \\
\hline Divorced & 11.0 \\
\hline Widowed & 5.6 \\
\hline \multicolumn{2}{|l|}{ Employed, \% } \\
\hline At onset of pain & 70.2 \\
\hline At consultation & 19.8 \\
\hline \multicolumn{2}{|c|}{ Highest education achieved, \% } \\
\hline High school & 44.0 \\
\hline College & 20.5 \\
\hline University & 25.5 \\
\hline
\end{tabular}

GTA (residing in the) Greater Toronto Area

pain clinics tend to have higher levels of functional impairment and psychosocial difficulties $(7,8)$; therefore, such patients are not representative of individuals in general who suffer from chronic pain. They also differ in demographic characteristics, including race or ethnicity, age, sex and socioeconomic status (9). However, many factors other than the pain and demographic characteristics of those attending pain clinics may influence demand for care, such as clinical expertise, needs of the catchment area (the area from which patients are referred to a clinic), referring physician's preference, patient preference, types of pain clinical services available, length of waiting list, funding considerations, etc.

The objective of the present study, the first of a series, is to outline the demographic distribution and pain characteristics of patients who present to a tertiary care, hospital-based pain clinic affiliated with the University of Toronto, Ontario. Patients referred to our program come from Toronto, the Greater Toronto Area (GTA) (a region of $7000 \mathrm{~km}^{2}$ that includes 25 municipalities, four regions and 5.6 million people, accounting for $41.8 \%$ of the total population of Ontario) and the province of Ontario at large, as well as other provinces.

\section{METHODS}

Data were collected from a consecutive series of 1242 new patients referred to the Comprehensive Pain Program (CPP) of the Toronto Western Hospital (a teaching hospital affiliated with the University of Toronto) at the University Health Network over the course of three years within the 2001 to 2004 time frame. Data collection and analysis were approved by the University Health Network Research Ethics Board. All demographic information was provided by the patients via intake questionnaires completed at the time of consultation (age, sex, place of residence, country of birth, language spoken at home, years of education, marital status, employment at the onset of pain and at the time of first consultation at the pain clinic, as well as the short form of the McGill Pain Questionnaire). Clinical information was obtained via a comprehensive history and detailed neuromusculoskeletal examination at the time of the examination. Additionally, information was obtained from a review of pertinent documentation (previous tests and interventions), as well as from follow-up visits and further investigations when needed. Each patient was seen and followed up by the same pain clinician. Detailed coding of neuropathic pain (NP) disorders, musculoskeletal (MSK) problems, visceral syndromes and complex syndromes was obtained based on a specified list of multiple disorders created for our data collection. Examples of complex syndromes include failed back surgery syndrome (FBSS) and thoracic outlet syndrome, because these entities are a complex mix of several pain types and mechanisms. Each patient could have more than one medical problem (listed separately). Furthermore, psychiatric comorbidity and determination of psychosocial factors were an important part of the clinical interview; the clinicians noted and recorded, in detail, the behaviours and psychosocial factors that could impact on pain perception and/or expression (eg, response of family members; catastrophizing, fear or pain avoidance behaviours; response bias to report pain, etc), as well as mood or anxiety disorders or other psychiatric comorbidies. The psychiatric diagnosis was based on the clinical interview, review of previous relevant files, and current or past medication use for mood or anxiety disorders. To ascertain the duration of pain before the consultation with the CPP, a random sample of 98 charts was reviewed.

The CPP physicians routinely use diagnostic categorization of pain disorders along the lines described in the 2000 DSM-IV-TR (1) to facilitate and guide treatment decision-making. Patients were, therefore, classified under one of the following diagnoses: pain disorder associated with a general medical condition, which does not constitute a mental disorder (Group I); pain disorder associated with both psychological factors and a general medical condition (Group II); and pain disorder associated with psychological factors (Group III). The latter is not considered by the team physicians as a diagnosis of exclusion, but requires a combination of detailed clinical information by history and physical examination findings, absence of positive investigations, and behavioural observations, including, but not limited to, degree of disability and its concordance with clinical findings and investigations, while mood or anxiety disorders and psychological or psychosocial variables were documented as stated earlier.

Statistical analyses were conducted to assess whether relationships were statistically significant using the appropriate statistics (eg, $t, F, \chi^{2}$ ); however, this is a retrospective study using a fairly large sample with no specific hypothesis testing. As such, these statistics provide only some indication, with at least a $\mathrm{P}<0.05$ level of statistical significance, of results that may not simply be due to chance distribution of the data.

\section{RESULTS}

A total of 1242 new patients were seen over a three-year period, and the demographic characteristics are summarized in Table 1. The female to male ratio was 1.33:1 (708 females and 534 males). One of three patients (395 versus 847 patients) came 
TABLE 2

Age distribution per type of pain (Groups I and II, n=951)

\begin{tabular}{|c|c|c|c|c|c|c|c|c|c|c|}
\hline & NP & MSK & Visceral & Mixed & NP/MSK & Other & No Dx & $\begin{array}{c}\text { Per cent of } \\
\text { male population }\end{array}$ & $\begin{array}{c}\text { Per cent of } \\
\text { female population }\end{array}$ & $\begin{array}{c}\text { Per cent of } \\
\text { CPP population }\end{array}$ \\
\hline$<20$ years & 4 & 1 & 0 & 0 & 0 & 0 & 2 & 0.23 & 1.15 & 0.74 \\
\hline 20-34 years & 33 & 45 & 5 & 7 & 18 & 6 & 5 & 10.9 & 13.85 & 12.51 \\
\hline $35-49$ years & 105 & 153 & 15 & 26 & 47 & 14 & 25 & 44.5 & 37.12 & 40.48 \\
\hline 50-64 years & 85 & 116 & 7 & 17 & 31 & 7 & 8 & 28.32 & 28.65 & 28.5 \\
\hline$>64$ years & 60 & 73 & 4 & 0 & 25 & 5 & 2 & 16.00 & 19.23 & 17.77 \\
\hline n (\%) & $287(30.18)$ & $388(40.80)$ & $31(3.26)$ & $50(5.26)$ & $121(12.72)$ & $32(3.37)$ & $42(4.42)$ & 100 & 100 & 100 \\
\hline
\end{tabular}

Values are expressed as numbers of patients, unless per cent is stated. The last three columns indicate only percentages of Group I (exclusively medical condition) and Group II (detectable biomedical condition, but disproportionate disability and psychological or psychiatric factors contributing to presentation) populations (n=951). CPP Comprehensive Pain Program; MSK Musculoskeletal pain; No Dx Data for which the specific medical diagnosis was missing from the records, while the physician had identified the patient as belonging to Group I or II; NP Neuropathic pain

to the clinic from outside the GTA. There were no significant differences observed between GTA and non-GTA patients in terms of female to male ratio, whether pain was nociceptive or neuropathic, or pain disorder classification.

\section{Age of presentation}

The mean $( \pm$ SD) age at presentation for all patients was $48.5 \pm 14.2$ years (range 13 to 96 years); however, non-GTA patients were significantly younger (mean age 46.3 years) than GTA patients (mean age 49.6 years, $t=3.87, \mathrm{P}<0.0001$ ). The most commonly affected age group was the 35 - to 49 -year age range ( $43 \%$ of the total CPP population cumulatively for both sexes, $n=1242$ ), followed by patients aged 50 to 64 years (constituting $27 \%$ of all pain patients, $n=1242$ ). Of the remainder, approximately one in seven patients either belonged to the 20 to 34-year age group or were older than 65 years. Despite the higher number of women referred to the CPP, the distribution of sexes was remarkably similar in all age groups except for a slight male preponderance in the peak group of 35 to 49 years. Details are presented in Table 2 .

\section{Marital status}

Data were available for 1157 patients. Twenty per cent of the patients were single, $58 \%$ were married, $5 \%$ were in a commonlaw relationship, $11 \%$ were separated or divorced, and $5.6 \%$ were widowed. The proportion of female to male patients in each of these categories was very similar, except in the widowed subgroup in which women significantly outnumbered men (female to male ratio 3:1).

\section{Employment}

Only $19.76 \%$ of the responders were employed at the time of CPP consultation (data available for 863 patients), contrasted with $70.2 \%$ who were employed at the start of pain-related problems (data available for 992 patients). Another 13.8\% were retired at the time of CPP consultation (compared with $11.5 \%$ at the onset of pain). Therefore, the rate of unemployment had increased from $16.9 \%$ at the onset of pain to $65.4 \%$ at the time of pain clinic consultation.

\section{Education}

Data were available for 1023 patients. Approximately 44\% of the patients had completed high school. Another $20.5 \%$ had some college education or had obtained a college degree, and $25.5 \%$ had achieved some university education or completed a university degree.
TABLE 3

Sex distribution per diagnostic classification $(n=1242)$

\begin{tabular}{lccc}
\hline & Total, $\mathbf{n}(\%)$ & Men, $\mathbf{n}(\%)$ & Women, $\mathbf{n}(\%)$ \\
\hline Group I & $317(25.52)$ & $154(28.84)$ & $163(23.00)$ \\
Group II & $634(51.04)$ & $277(51.87)$ & $357(50.40)$ \\
Group III & $260(20.93)$ & $88(16.48)$ & $172(24.29)$ \\
Miscellaneous & $32(2.58)$ & $15(2.81)$ & $16(2.26)$ \\
Total & $1242(100.00)$ & $534(100.00)$ & $708(100.00)$ \\
\hline
\end{tabular}

Group I Exclusively medical condition; Group II Detectable biomedical condition, but disproportionate disability and psychological or psychiatric factors contributing to presentation; Group III Vague or diffuse complaints and significant disability in the absence of clinically detectable biomedical conditions, while significant psychological or psychiatric factors contribute to presentation; Miscellaneous Malingering, not yet diagnosed or missing data

\section{Country of birth}

More than one-half of the patients were born in Canada $(58.7 \%, n=729)$. The remainder were born outside Canada, primarily in southern Europe, the United Kingdom, eastern Europe, the Caribbean, and south-central Asia (primarily India and Pakistan). Ethnocultural data are presented and discussed in detail in the companion paper (10).

\section{Diagnostic categorization}

Using the DSM-IV-TR pain disorder classification, just over one-half of all patients (51\%) were diagnosed with both significant medical and psychological factors, and were classified into Group II (similar for both men and women), whereas $20.9 \%$ were considered to present primarily with psychological factors and $25.5 \%$ were considered to present primarily with medical factors. There were significant sex differences in terms of pain disorder classification (Pearson's $\chi^{2}=13.47 ; \mathrm{P}<0.001$ ). Men tended to have higher levels of demonstrable organic pathology, with $28.84 \%$ of the men classified into Group I versus $23 \%$ of the women. More women than men (24.9\% versus $16.48 \%$, respectively) were classified into Group III (vague or diffuse symptoms in the absence of detectable biomedical pathology with significant psychological factors involved in presentation). Furthermore, statistically significant age differences existed with regard to age for the three pain disorder groups $(\mathrm{F}=42.13, \mathrm{P}<0.001)$. Those with demonstrable pathology and no undue psychological factors were older (mean [ $\pm \mathrm{SD}$ ] age $54 \pm 16$ years) than those with both medical and psychological factors (mean age $48 \pm 14$ years) or those with only psychological factors (mean age $43 \pm 11$ years). The results are presented in Table 3. 
TABLE 4

The most common medical problems in patients with a medical condition (Group I, $\mathrm{n}=951$ )

\begin{tabular}{|c|c|c|c|c|c|c|c|c|}
\hline & NP only & MSK only & Visceral only & Complex (TOS, FBSS) & NP/MSK & Other & Missing data & Total \\
\hline Men, \% (n) & 33.41 (144) & $35.73(154)$ & $2.55(11)$ & $6.26(27)$ & $15.55(67)$ & $3.01(13)$ & $3.48(15)$ & $100.00(431)$ \\
\hline Women, \% (n) & $27.50(143)$ & $45.00(234)$ & $3.85(20)$ & $4.42(23)$ & $10.38(54)$ & $3.65(19)$ & $5.19(27)$ & $100.00(520)$ \\
\hline Total, \% (n) & $30.18(287)$ & $40.80(388)$ & $3.26(31)$ & $5.26(50)$ & $12.72(121)$ & $3.36(32)$ & $4.42(42)$ & $100.00(951)$ \\
\hline
\end{tabular}

FBSS Failed back surgery syndrome; MSK Musculoskeletal pain; NP Neuropathic pain; TOS Thoracic outlet syndrome

TABLE 5

Types of syndromes in $\mathbf{3 8 8}$ patients with musculoskeletal (MSK) pain only

\begin{tabular}{lccc}
\hline Syndrome & $\begin{array}{c}\text { Men, \% } \\
(\mathbf{n = 1 5 4 )}\end{array}$ & $\begin{array}{c}\text { Women, \% } \\
(\mathbf{n = 2 3 4 )}\end{array}$ & $\begin{array}{r}\text { Total, \% } \\
\text { (n=388) }\end{array}$ \\
\hline Mechanical back pain & 30.5 & 22.7 & 25.77 \\
More than one MSK diagnosis & 24.0 & 26.0 & 25.26 \\
Other (tendinitis, epicondylitis, etc) & 11.7 & 12.8 & 12.37 \\
Osteoarthritis & 11.0 & 10.7 & 10.82 \\
Shoulder disorders & 8.4 & 5.6 & 6.70 \\
Regional myofascial syndrome & 2.6 & 7.3 & 5.41 \\
Mechanical neck pain & 3.3 & 5.1 & 4.38 \\
Migraines & 1.3 & 3.0 & 2.32 \\
Spinal stenosis & 2.6 & 1.7 & 2.06 \\
Chest wall pain/costochondritis & 1.3 & 2.1 & 1.80 \\
Inflammatory arthropathies & 0.6 & 1.7 & 1.29 \\
Ischemic pain/vascular claudication & 2.0 & 0.4 & 1.03 \\
Joint/skin infection & 0.6 & 0.9 & 0.77 \\
Total & 100.0 & 100.0 & 100.00 \\
\hline
\end{tabular}

Types of biomedical disorders

In Groups I and II (both with detectable biomedical pathology, $\mathrm{n}=951$ ), the most common disorders were MSK in origin (40.80\%), followed by NP syndromes (30.18\%). Additionally, one-sixth of the patients had more than one pathology (in most cases MSK and neuropathic combined, reflective of the complex nature of pain problems referred to the centre). It should be noted that patients with multisite pain due to several distinct MSK or neuropathic pathologies were classified into Group I or Group II, while patients with diffuse (widespread) body pain in the absence of relevant biomedical pathology and with concurrent psychiatric or psychosocial comorbidities were classified into Group III. In Groups I and II, women outnumbered men with regard to MSK pathology ( $45 \%$ versus $35.73 \%$, respectively), while the opposite was true for NP pain syndromes (affecting $33.41 \%$ of men versus $27.5 \%$ of women, respectively; Pearson's $\left.\chi^{2}=5.29 ; \mathrm{P}<0.05\right)$. The results are shown in Table 4.

Table 5 provides a detailed list of the most prominent MSK disorders in the present population. Mechanical back pain without sciatica and more than one discreet MSK problem were the most prevalent disorders affecting one-quarter of the patients in Group I and Group II with an exclusively MSK pathology. In those patients with an exclusively neuropathic pathology, complex regional pain syndrome type I (previously known as reflex sympathetic dystrophy) affected $14.3 \%$ of patients in Group I and Group II, followed by limb nerve injury $(9.8 \%)$, spinal cord injury (6.6\%) and more than one NP injury in combination (6.3\%). Complex regional pain syndrome type II was included in the group of peripheral nerve injuries, because it was very hard to separate localized versus more diffuse symptoms in the
TABLE 6 Types of neuropathic syndromes in 287 patients with
neuropathic pain (NP) only

\begin{tabular}{lccc}
\hline Syndrome & $\begin{array}{c}\text { Men, \% } \\
\text { (n=144) }\end{array}$ & $\begin{array}{c}\text { Women, \% } \\
\text { (n=143) }\end{array}$ & $\begin{array}{c}\text { Total, \% } \\
\text { (n=287) }\end{array}$ \\
\hline Complex regional pain syndrome & 10.4 & 18.2 & 14.29 \\
Peripheral nerve injury (limb) & 7.6 & 11.9 & 9.76 \\
Spinal cord injury & 9.7 & 3.5 & 6.62 \\
More than one NP diagnosis & 8.3 & 4.2 & 6.27 \\
Lumbar radiculopathy & 6.3 & 3.5 & 4.88 \\
Diabetic neuropathy & 5.6 & 4.2 & 4.88 \\
Postherpetic neuralgia & 4.2 & 5.6 & 4.88 \\
Phantom limb/stump pain & 5.6 & 3.5 & 4.53 \\
Myelopathy & 4.9 & 3.5 & 4.18 \\
Poststroke pain syndrome & 4.2 & 3.4 & 3.83 \\
Neuroma & 3.5 & 3.5 & 3.50 \\
Other neuropathy & 3.5 & 2.8 & 3.14 \\
Parkinson's disease - basal ganglia & 2.8 & 2.1 & 2.44 \\
Cervical radiculopathy & 1.4 & 2.8 & 2.09 \\
Brachial plexus injury & 2.8 & 1.4 & 2.09 \\
Post cardiac bypass surgery & 2.8 & 1.4 & 2.09 \\
Abdominal nerve injury & 2.1 & 1.4 & 1.74 \\
Post polio syndrome & 0.7 & 2.1 & 1.39 \\
llioinguinal nerve injury & 1.4 & 0.7 & 1.05 \\
Trigeminal neuralgia* & - & 1.4 & 0.70 \\
NP nonspecified/rare syndrome ${ }^{\dagger}$ & 12.5 & 18.9 & 15.68 \\
(less than 1\% for each) & & & \\
Total & 100.0 & 100.0 & 100.00 \\
\hline
\end{tabular}

*Trigeminal neuralgia is listed specifically to emphasize how rare it is in our clinic (multiple sclerosis in this cohort is also below 1\%). ${ }^{\dagger}$ Examples of rare syndromes are Friedreich's ataxia, Charcot-Marie-Tooth disease, diabetic NP cachexia, etc; an example of a nonspecified NP syndrome is diffuse arm pain with patches of altered sensation after electrocution

presence of documented nerve injury. A detailed list of NP syndromes and their prevalences according to sex and collectively in Groups I and II are shown in Table 6. Both MSK and NP data are derived from patients in Groups I and II.

Elderly patients

Approximately one in seven patients was older than 65 years. This group almost exclusively presented with discernible biomedical pathology (50.5\% were classified in Group I and 42.3\% in Group II), with NP disorders predominant in men and MSK disorders predominant in women. Further details pertaining to the older than 65-year age group will be published separately (Dr B Yegneswaran, personal communication).

Specific pain problems

FBSS, classified separately under mixed or complex syndromes, was seen in 53 patients ( $4.3 \%$ of the overall CPP population), including 32 men and 21 women. Altogether, 
three-quarters of these patients had associated psychological or psychiatric factors (similar to the general CPP population). Interestingly, FBSS was much more prevalent in Canadianborn than foreign-born men (10).

Diffuse (or total) body pain, in the absence of specific detectable pathology, was present in 24 men and 88 women, corresponding to $5.9 \%$ and $13.7 \%$ of the total male and female CPP populations, respectively. Diffuse body pain was, therefore, over twice as common in women than men (Pearson's $\left.\chi^{2}=19.43, \mathrm{P}<0.001\right)$. Altogether, such diffuse body pain affected $27.3 \%$ of the men and $51.2 \%$ of the women in Group III, which consisted of 88 men and 172 women $(n=260)$.

\section{Duration of pain before the CPP consultation}

The mean duration of pain (derived from an analysis of 98 randomly selected charts) was 7.8 years for both men and women (ranging from 0.1 years to 33 years for women and 0.5 years to 50 years for men). When pain durations were re-analyzed based on diagnostic categorization, mean durations for men and women were, respectively, 4.3 years and 10.5 years for Group I, 9.5 years and 7.6 years for Group II, and 9.5 years and 3.8 years for Group III. Analysis of pain duration also showed that $5 \%$ of the patients were referred and seen in the acute or subacute stage of pain (within one to six months), and $10 \%$ were seen within six to 12 months from the onset of pain. These consultations were actually performed within weeks from the referral, because they were deemed urgent. Overall, while the average waiting list for the CPP is approximately six to eight months, there is substantial flexibility for those that are deemed as urgent to be seen within weeks or even a few days (primarily very young and very old patients with CNCP after cancer treatment, with NP and pain of recent onset).

\section{DISCUSSION}

Our data on 1242 consecutive new patients who were referred to the CPP represent the first detailed information known from a Canadian pain clinic.

Approximately three-quarters of the patients attending our clinic had detectable biomedical pathology (Groups I and II). Similarly, in approximately three-quarters of our patients, pain was associated with and augmented by psychological or psychiatric factors (Groups II and III). Our data are in accordance with the existing literature, which shows that CNCP patients in pain clinics are more complex than pain sufferers in the community, with much higher levels of functional impairments and psychosocial difficulties $(6,7)$, as well as 'abnormal illness behaviour' $(11,12)$.

Special mention should be made of the older patient group (older than 65 years), who presented with striking levels of physical pathology, primarily NP in men and MSK in women. It is obvious that the older group is different than the other pain groups attending our program, and this is in accordance with published literature, in which chronic pain in the elderly is viewed as "a bird of different colour" $(13,14)$.

Our data also show that chronic pain primarily affects the most productive age group (mid-40s) and is associated with high levels of distress and unemployment, even when the patients have higher education.

The higher attendance rate of women in our pain program is consistent with literature that confirms that women in North America have a higher rate of health care use than men (15). The prevalence of most pain conditions is higher among women than men $(16,17)$. These differences are based on a complex mix of biological (hormonal and genetic), psychological and socioenvironmental factors (18). In general, the female preponderance in our study with regard to the presence of psychological or psychosocial factors is supported by existing literature, which shows that female sex is one of the risk factors associated with a psychiatric diagnosis in a pain clinic population (19), and that features of somatization predict the onset of chronic widespread pain (20), which was two times more prevalent in women than men in our population.

Traditionally, NP is considered to affect $10 \%$ of the chronic pain population; however, the only general population study in the literature, published recently from the United Kingdom (21), suggested a much higher prevalence, with NP possibly accounting for $17 \%$ of all chronic pain and affecting $8 \%$ of the general population. In our clinic, NP alone or in combination with nociceptive pain affected more than $43 \%$ of Group I and II patients, and, collectively, 33\% of the total CPP population. Therefore, one can conclude that, at least in our clinic, NP is over-represented. Our data are in agreement with published information indicating that over-representation of NP in hospital-based pain clinics seems to be the rule rather than the exception (22). This over-representation may be actually indicative of the difficulty in managing NP in the community.

While FBSS seems to be very common in some pain clinics, constituting up to one-quarter of all patients (Dr Dwight Moulin, personal communication), this affected only a minority of our patients. This is indicative of the diverse and specific populations seen in pain clinics, and of the fact that our data may not be generalizable to other settings.

We appreciate that the use of the DSM-IV-TR pain disorder classification system may be problematic and controversial. There is poor understanding or consensus about what types of psychological factors are involved in the onset, maintenance, severity or exacerbation of pain (despite voluminous literature indicating that such factors can be important). The distinction between biomedical and psychological bases for pain is somewhat artificial, reflecting the longstanding problem of mindbody dualism. Nonetheless, it is important for clinicians to weigh appropriately the biomedical versus psychological contribution to the pain experience to direct management by employing medical treatments, psychological treatments or both, when indicated. Lack of understanding of underlying biomedical and/or psychological processes can lead to unnecessary or ineffective interventions and iatrogenic complications. Nevertheless, in our clinic, we have attempted to better define psychological factors (as stated in Methods) to assist with our clinical judgment regarding diagnosis and subsequent treatment. A position paper detailing further our experience working with this classification system, which we have enhanced to make it more specific, and our perspective on possible revisions of the traditional DSM IV-TR classification, is in preparation.

Our waiting list of six months seems to be very short compared with other Toronto- and Canadian-based clinics, where the waiting list may reach two to three years (23) for a pain consultation $(24,25)$. We do maintain flexibility to accommodate specific patients, because $15 \%$ of our population is seen within weeks to months from the onset of pain. Despite the fact that our program is one of the oldest in the country, established in 1982 with both outpatient and inpatient (investigational) services, we have been able to shorten our waiting list 
very substantially over the past three years using very specific measures to curtail the extremely high 'no-show' rate of pain patients and the number of inappropriate referrals. These measures are as follows:

- No patient is seen unless a proper, concise medical referral is received, accompanied by medical documentation of previous investigations, surgical reports, etc. The referring physician is notified if the referral is incomplete and asked to furnish appropriate information.

- All appropriately referred patients are placed on a frequently updated database, based on time of referral.

- The list is reviewed by the CPP staff, and patients deemed urgent are placed on an 'urgent' list (patients older than 65 years, patients younger than 25 years, NP in patients, as well as CNCP patients after cancer treatment). Such patients are usually called by phone. All other patients are contacted in chronological order by letter. If they do not respond within one month from receipt of the letter, their referral file is sent back to the patient's physician, and the process must start over.

- Patients are notified that cancellations must be made $48 \mathrm{~h}$ before the appointment. Two no-shows result in automatic permanent removal from the list.

Of great importance to the survival of our program is our funding arrangement with the Ministry of Health and LongTerm Care in Ontario. Chronic pain patients are complex and demand extensive time and resources. The fee-for-service remuneration system in Ontario is incapable of sustaining pain clinics that need to operate with interdisciplinary and multidisciplinary teams. Our program has been funded by the alternative payment program of the Ministry of Health since 1990. Such a funding arrangement has recognized not only the need for physician remuneration (based on salary and quotas), but also the tremendous need for support staff (psychological services, secretarial support, clinical coordination, etc) and office expenses. Needless to say, the funding arrangement has not kept up with today's cost of living, salary ranges and operating expenses. This has resulted in a constant struggle for the program to obtain additional sources of funding from external sources (medicolegal work, preceptorships, fundraising, etc). The hospital itself primarily provides space facilities and maintenance. In this era of increasing constrictions in health care provisions, with hospital budget deficits ballooning and overwhelming service reductions, the sole reason for the survival of our program is the independent funding arrangement we have with the Ontario government (despite the fact that it literally has been frozen for several years). Without this arrangement, there is no doubt that chronic pain services in our institution would have followed, long ago, the fate of pain programs based in other hospitals, which have been curtailed or outright eliminated, unless they are able to be self-sufficient by billing for services.

Given the very high prevalence of chronic pain and the scarcity of pain clinics, the bulk of chronic pain management falls on the shoulders of primary care physicians (26), who are truly the 'gatekeepers'. However, major obstacles in the management of chronic pain faced by primary care physicians relate to a lack of formal education in chronic pain, and insufficient funding and time for complex patients who require labour-intensive and lengthy encounters with practitioners. If chronic pain were better diagnosed and managed earlier at the primary care level, we strongly believe that a much smaller percentage of such patients would require pain clinic consultation. Additionally, serious underfunding and understaffing of pain clinics in Ontario and other provinces compound the difficulties primary care physicians and pain patients experience, because the clinical waiting lists may be three to five years long in certain parts of Ontario and Canada (23-25). The Calgary, Alberta, region of western Canada constitutes the prototype of integrated approach and delivery of chronic pain services at multiple levels of the system (27). Furthermore, Quebec and Nova Scotia (28) have recently accomplished major steps in recognizing the need for integration of pain services. Unfortunately, Ontario, the province with the largest population in Canada and home to 38\% of all Canadians, is seriously behind with regard to pain diagnostic and management services at every level (from primary care to hospital pain clinics) and lacks even a simple plan for integration of pain services.

Our study has several limitations. First, it was carried out at one hospital pain clinic; therefore, our data are not necessarily generalizable and may not represent other pain clinic populations. Second, our diagnostic and management approaches may be different from those of other clinics. Finally, given the fact that our clinic is a tertiary care centre, referral bias has to be taken into account when interpreting our results. Such referral biases include our association with the hospital's neuroscience centre, the fact that we service Ontario and not just downtown Toronto, preferences of referring physicians, type of facilities, patient preferences, etc.

Nevertheless, our data constitute the first detailed Canadian report regarding demographic and pain characteristics of patients attending a tertiary care pain program, including our companion paper, which deals with important ethnic considerations (10). Similar studies from other pain clinics and centres will help us to understand the complexity and types of problems faced by chronic pain patients, pain practitioners and pain facilities in Ontario and other regions of Canada.

\section{REFERENCES}

1. American Psychiatric Association. Diagnostics and Statistical Manual of Mental Disorders, Fourth Edition - Text Revision. Washington, DC: American Psychiatric Association, 2000.

2. Aronoff GM, Evans WO, Enders PL. A review of follow-up studies of multidisciplinary pain units. Pain 1983;16:1-11.

3. Gatchel RJ, Epker J. Psychosocial predictors of chronic pain and response to treatment. In: Gatchel RJ, Turk DC, eds. Psychosocial Factors in Pain: Critical Perspectives. New York: Guilford Press, 1999:412-34.

4. Ospina M, Harstall C. Prevalence of Chronic Pain: An Overview. Edmonton: Alberta Heritage Foundation for Medical Research, 2002. <http://www.ihe.ca/documents/hta/prevalence_chronic_ pain.pdf $>$ (Version current at April 17, 2007).

5. Becker N, Hojsted J, Sjogren P, Eriksen J. Sociodemographic predictors of treatment outcome in chronic non-malignant pain patients. Do patients receiving or applying for disability pension benefit from multidisciplinary pain treatment? Pain 1998;77:279-87.

6. Turk DC, Rudy TE, Sorkin BA. Neglected topics in chronic pain treatment outcome studies: Determination of success. Pain 1993;53:3-16.

7. Crook J, Tunks E, Rideout E, Browne G. Epidemiologic comparison of persistent pain sufferers in a specialty pain clinic and in the community. Arch Phys Med Rehabil 1986;67:451-5.

8. Crook J, Weir R, Tunks E. An epidemiological follow-up survey of persistent pain sufferers in a group family practice and specialty pain clinic. Pain 1989;36:49-61. 
9. Allison JJ, Kiefe CI, Centor RM, Box JB, Farmer RM. Racial differences in the medical treatment of elderly Medicare patients with acute myocardial infarction. J Gen Intern Med 1996;11:736-43.

10. Mailis-Gagnon A, Yegneswaran B, Nicholson K, et al. Ethnocultural and sex characteristics of patients attending a tertiary care pain clinic in Toronto, Ontario. Pain Res Manag 2007;12:101-106.

11. Pilowsky I, Chapman CR, Bonica JJ. Pain, depression, and illness behavior in a pain clinic population. Pain 1977;4:183-92.

12. Roy R, Thomas M, Berger S. A comparative study of Canadian nonclinical and British pain clinic subjects. Clin J Pain 1990;6:276-83.

13. Weiner DK, Rudy TE. Attitudinal barriers to effective treatment of persistent pain in nursing home residents. J Am Geriatr Soc 2002;50:2035-40.

14. Weiner DK, Rudy TE, Gaur S. Are all older adults with persistent pain created equal? Preliminary evidence for a multiaxial taxonomy. Pain Res Manag 2001;6:133-41.

15. Health Status of Canadians: Report of the 1991 General Social Survey. Cat 0836-043X, No 8. Ottawa: Statistics Canada, 1994.

16. Unruh AM. Gender variations in clinical pain experience. Pain 1996;65:123-67.

17. Berkley KJ. Sex differences in pain. Behav Brain Sci 1997;20:371-80.

18. Meana M, Cho R, DesMeules M. Chronic pain: The extra burden on Canadian women. BMC Womens Health 2004;4(Suppl 1):S17.

19. Tyrer SP, Capon M, Peterson DM, Charlton JE, Thompson JW. The detection of psychiatric illness and psychological handicaps in a British pain clinic population. Pain 1989;36:63-74.
20. McBeth J, Macfarlane GJ, Benjamin S, Silman AJ. Features of somatization predict the onset of chronic widespread pain: Results of a large population-based study. Arthritis Rheum 2001;44:940-6

21. Torrance N, Smith BH, Bennett MI, Lee AJ. The epidemiology of chronic pain of predominantly neuropathic origin. Results from a general population survey. J Pain 2006;7:281-9.

22. Chaudakshetrin P. A survey of patients with neuropathic pain at Siriraj Pain Clinic. J Med Assoc Thai 2006;89:354-61.

23. Clark AJ, Beauprie I, Clark LB, Lynch ME. A triage approach to managing a two year wait-list in a chronic pain program. Pain Res Manag 2005;10:155-7.

24. Politics Hurts: A Life of Pain, Day 4. Ottawa Sun 2005 Oct 23.

25. Dobkin PL, Boothroyd LJ. Management of Chronic Non-Cancer Pain: Organization of Health Services. Quebec: AETMIS, 2006.

26. College of Physicians and Surgeons of Ontario. Evidence-based Recommendations for Medical Management of Chronic NonMalignant Pain: Reference Guide for Clinicians. $<$ http://www.cpso.on.ca/Publications/pain.htm> (Version current at April 17, 2007)

27. Rashiq S, Barton P, Harstall C, Schopflocher D, Taenzer P. The Alberta Ambassador Program: Delivering Health Technology Assessment results to rural practitioners. BMC Med Educ 2006;6:21.

28. Nova Scotia Chronic Pain Working Group. Action Plan for the Organization and Delivery of Chronic Pain Services in Nova Scotia, 2006. <http://www.gov.ns.ca/heal/downloads/ActionPlan PostSLTJuly192006.pdf> (Version current at April 17, 2007). 


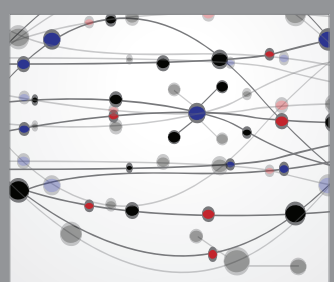

The Scientific World Journal
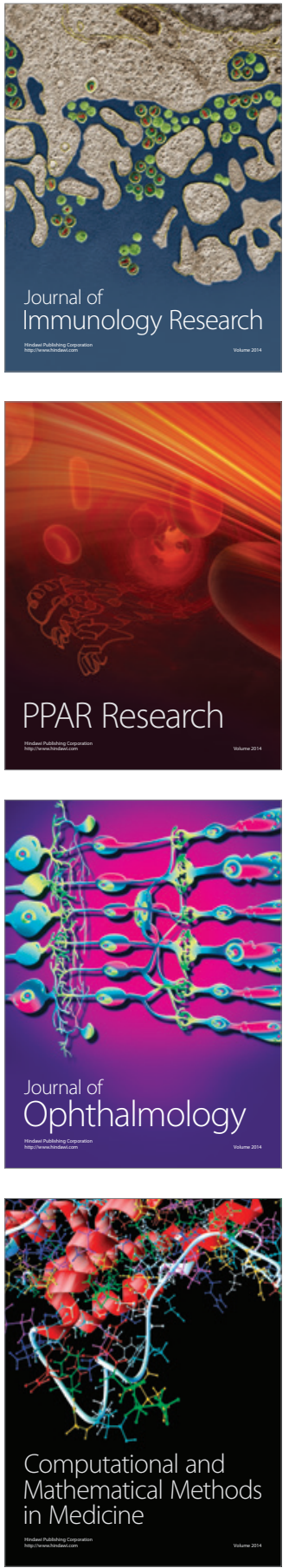

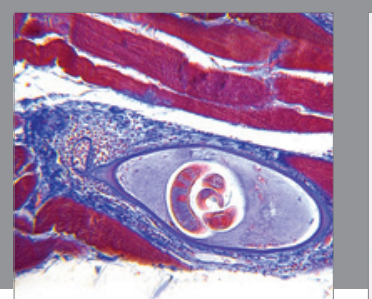

Gastroenterology Research and Practice

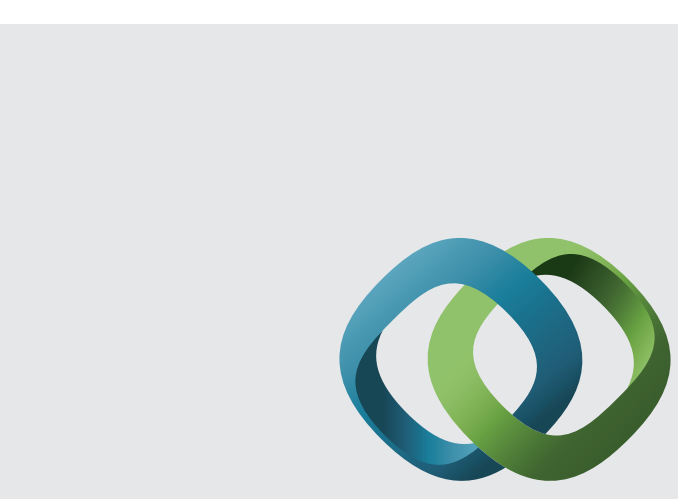

\section{Hindawi}

Submit your manuscripts at

http://www.hindawi.com
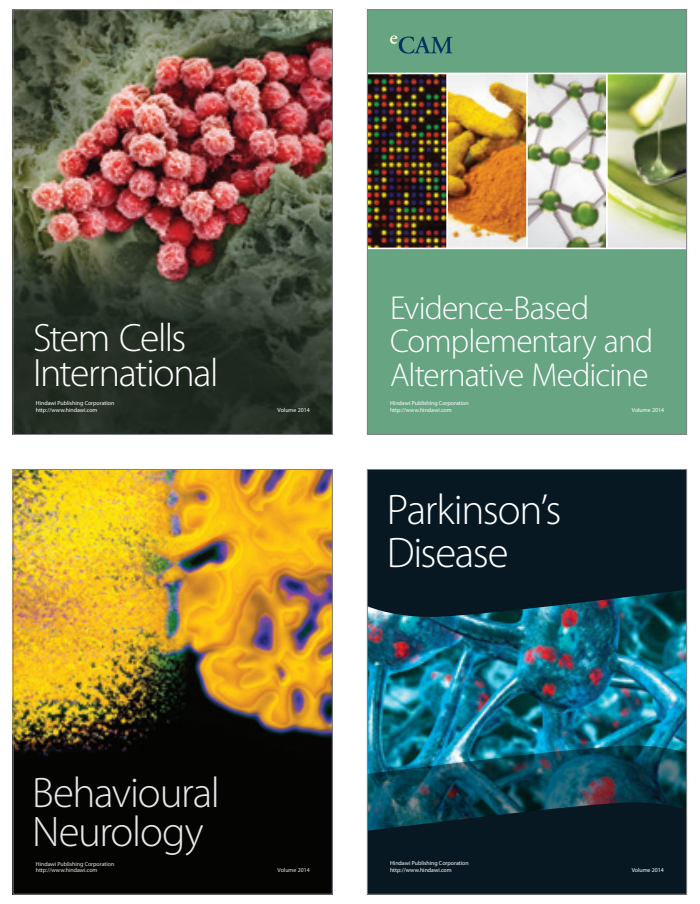
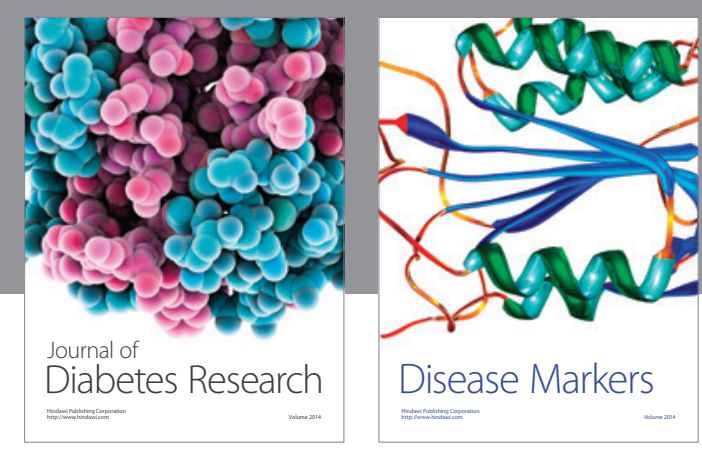

Disease Markers
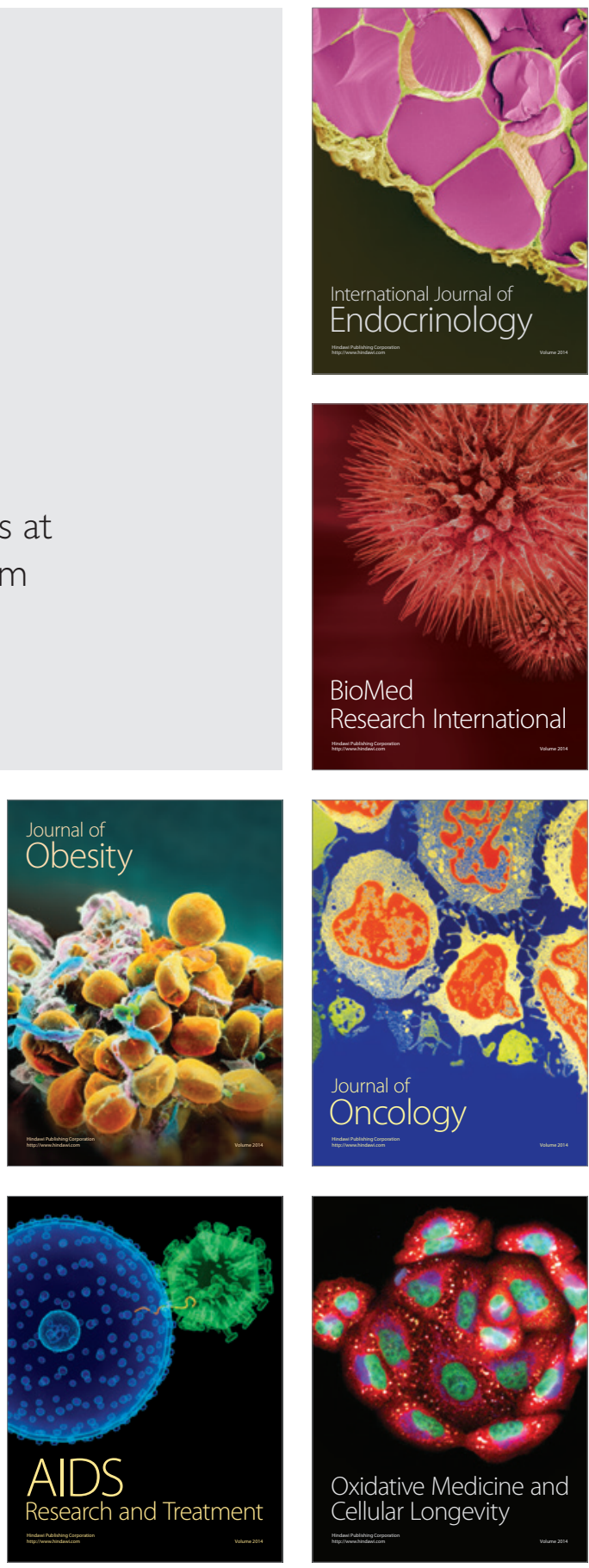